\title{
Hyperuricemia and Associated Factors in Children with Chronic Kidney Disease: A Cross-Sectional Study
}

\author{
Jie $\mathrm{Xu}^{\dagger}{ }^{\dagger}$, Lingxiao Tong ${ }^{\dagger}$ and Jianhua Mao * \\ Department of Nephrology, The Children's Hospital, Zhejiang University School of Medicine, National Clinical \\ Research Center for Child Health, \#57 Zhugan Lane, Hangzhou 310003, China; 11918401@zju.edu.cn (J.X.); \\ 11718193@zju.edu.cn (L.T.) \\ * Correspondence: maojh88@zju.edu.cn \\ † These authors contributed equally to this paper.
}

Citation: Xu, J.; Tong, L.; Mao, J. Hyperuricemia and Associated Factors in Children with Chronic Kidney Disease: A Cross-Sectional Study. Children 2022, 9, 6. https:// doi.org/10.3390/children9010006

Academic Editor: Yohei Ikezumi

Received: 22 November 2021

Accepted: 20 December 2021

Published: 23 December 2021

Publisher's Note: MDPI stays neutral with regard to jurisdictional claims in published maps and institutional affiliations.

Copyright: (c) 2021 by the authors Licensee MDPI, Basel, Switzerland. This article is an open access article distributed under the terms and conditions of the Creative Commons Attribution (CC BY) license (https:// creativecommons.org/licenses/by/ $4.0 /)$.

\begin{abstract}
Background: Hyperuricemia is increasingly recognized as a risk factor for chronic kidney disease (CKD) just in adults. The purpose of this study was to investigate the clinical characteristics of hyperuricemia and its associated factors in Chinese children with CKD at a single center. Methods: A cross-sectional study of 170 CKD children collected from the Department of Nephrology, The Zhejiang University Children's Hospital was conducted. The clinical data, including anthropometric data, blood pressure measurements, and biochemical parameters, were recorded and analyzed retrospectively. The factors associated with hyperuricemia in CKD children were evaluated by Pearson and Spearman correlation analysis and multiple logistic regression analysis. Results: The mean age was $9.79 \pm 4.10$ years, and 72 (42.35\%) were girls. Higher blood urea nitrogen (BUN), serum creatinine, cystatin C, D-dimer, lower hemoglobin, albumin, and estimated glomerular filtration rate (eGFR) were significantly associated with higher serum uric acid (SUA). In multiple logistic regression analysis, anemia and higher BUN were both positively associated factors, whereas eGFR $\geq 90 \mathrm{~mL} / \mathrm{min} / 1.73 \mathrm{~m}^{2}$ was a negatively associated factor for subjects with SUA $\geq 390 \mu \mathrm{mol} / \mathrm{L}(6.5 \mathrm{mg} / \mathrm{dL})$. Conclusions: SUA was significantly associated with kidney risk factors in CKD children. Monitoring and controlling SUA, Hb, BUN, and Scr levels in CKD children may help to prevent the progression of CKD.
\end{abstract}

Keywords: serum uric acid; hyperuricemia; chronic kidney disease; children

\section{Introduction}

Hyperuricemia is a chronic purine metabolic disorder mainly because of excessive production of uric acid and/or decreased renal excretion. Recently, the prevalence of hyperuricemia has markedly increased among children worldwide [1-3]. Many clinical and epidemiological studies have suggested that increased serum uric acid (SUA) levels may be closely associated with metabolic syndrome, chronic kidney disease (CKD), and cardiovascular disease [4-9]. Indeed, hyperuricemia in children has become a major public health issue and is currently gaining more and more attention.

CKD causes a substantial burden to individuals, families, and health care systems due to the reduced quality of life, dialysis, and even kidney transplantation [10]. Hyperuricemia and CKD probably influence one another in many ways, depending on multiple mechanisms. Impaired kidney function may contribute to hyperuricemia because of the decreased renal excretion [11]. On the other hand, hyperuricemia plays an important role in the development and progression of CKD due to several factors, such as vascular smooth cell proliferation, endothelial dysfunction, impaired endothelial nitric oxide production, and inflammation $[4,12-14]$. However, what factors may be associated with hyperuricemia in CKD children remains uncertain.

The aims of the cross-sectional study were to provide reliable information on the clinical characteristics of hyperuricemia in children with CKD from a pediatric nephrol- 
ogy department and to further evaluate the association between hyperuricemia and its associated factors in Chinese CKD children.

\section{Materials and Methods}

\subsection{Study Sample}

We collected the records of 170 children and adolescents diagnosed with CKD hospitalized at Zhejiang University Children's Hospital between January 2013 and September 2020. The patients had a mean age of $9.79 \pm 4.10$ years, and 72 (42.35\%) were girls. Children who had taken treatments that could affect uric acid metabolism, such as urate-lowering drugs including allopurinol and benzbromarone, were excluded. Subjects with a history of severe infection, cardiovascular disease, liver injury, kidney transplantation, dialysis, tumor, and malignant hematological disease were excluded from the study. The ethics committee of Zhejiang University Children's Hospital approved the study.

\subsection{Study Measures and Laboratory Methods}

Participants provided clinical data, including anthropometric data, blood pressure (BP) measurements, biochemical parameters, and prescription medications. BP and anthropometric data, including height and weight, were undertaken by the professional nurses. The biochemical parameters including hemoglobin $(\mathrm{Hb})$, albumin (Alb), total cholesterol (TC), triglycerides (TG), blood urea nitrogen (BUN), serum uric acid (SUA), cystatin C (Cys C), serum creatinine (Scr), fibrinogen (Fib) and D-Dimer (DD) were measured. The estimated glomerular filtration rate (eGFR) was calculated using the Schwartz formula [15] as follows: eGFR $\left(\mathrm{mL} / \mathrm{min} / 1.73 \mathrm{~m}^{2}\right)=k \times L /$ Scr. The value of $k$ is a constant varying with age and sex, $L$ stands for height $(\mathrm{cm})$, and $S c r$ stands for serum creatinine $(\mu \mathrm{mol} / \mathrm{L})$. Urine was collected for $24 \mathrm{~h}$, and $24 \mathrm{~h}$ urine protein quantity (24HUPr) was measured. The professional doctors collected the medical history of participants, including etiological factors, prescription drugs, and family history.

Obesity was estimated by body mass index (BMI) more than the 95th percentile based on age and sex [16]. Hypertension was defined as average measured systolic blood pressure (SBP) and/or diastolic blood pressure (DBP) $\geq 95$ th percentile according to sex, age, and height percentiles [17]. Anemia in children with CKD was diagnosed if $\mathrm{Hb}$ concentration is $<110 \mathrm{~g} / \mathrm{L}$ in children $0.5-5$ years, $<115 \mathrm{~g} / \mathrm{L}$ in children $5-12$ years, and $<120 \mathrm{~g} / \mathrm{L}$ in children 12-15 years [18]. CKD was defined as abnormalities of renal structure or function lasting for at least 3 months and can be classified into 5 stages based on the Kidney Disease: Improving Global Outcomes (KDIGO) guidelines [19]. Congenital anomalies of the kidney and urinary tract (CAKUT) included obstructive uropathy, aplasia/hypoplasia/dysplasia, and reflux nephropathy [20]. Those whose length or height $z$-score was 2 SD score or more below the mean height based on age, sex, and population were diagnosed with short stature [21]. Those renal osteopathy patients were diagnosed with chronic kidney disease-mineral and bone disorder (CKD-MBD), including renal osteodystrophy and extra-skeletal calcification due to the abnormalities of bone mineral metabolism [18]. Elevated TC was defined as TC was $\geq 200 \mathrm{mg} / \mathrm{dL}$ in children and adolescents. Elevated TG was defined as TG was $\geq 100 \mathrm{mg} / \mathrm{dL}$ in children $0-9$ years and $\geq 130 \mathrm{mg} / \mathrm{dL}$ in children 10-19 years [22]. In children, SUA levels increased with age, and there were no universally accepted clinical diagnostic criteria of hyperuricemia. In adults, hyperuricemia was defined that SUA levels were $\geq 416.0 \mu \mathrm{mol} / \mathrm{L}(7.0 \mathrm{mg} / \mathrm{dL})$ in male and $\geq 357.0 \mu \mathrm{mol} / \mathrm{L}(6.0 \mathrm{mg} / \mathrm{dL})$ in female [23]. The China National Survey of Chronic Kidney Disease reported that SUA levels of adults with CKD were $387.0 \pm 129.5 \mu \mathrm{mol} / \mathrm{L}$ [24]. What is more, studies indicated that SUA levels at $6.3-6.5 \mathrm{mg} / \mathrm{dL}$ contributed to the progression of CKD $[25,26]$. So, in this study, elevated SUA was defined as $\geq 390 \mu \mathrm{mol} / \mathrm{L}(6.5 \mathrm{mg} / \mathrm{dL})$, also representing the approximate IQR of the distribution. 


\subsection{Statistical Analysis}

The continuous data were presented as mean $\pm \mathrm{SD}$, and categorical data were presented as numbers and percentages. In the case of nonparametric distribution, data (including BUN, Scr, and 24HUPr) were presented as a median (interquartile range, IQR). Student's $t$-tests and Mann-Whitney U test were used to compare continuous characteristics by sex at baseline. Categorical characteristics were compared by $\chi^{2}$ tests. Characteristics with a skewed distribution (including age, BMI, Alb, TC TG, Fib, and DD) were reciprocaltransformed, square-root-transformed, or log-transformed as appropriate. Serum uric acid was categorized as $<390 \mu \mathrm{mol} / \mathrm{L}(6.5 \mathrm{mg} / \mathrm{dL}), 390-540 \mu \mathrm{mol} / \mathrm{L}$ (6.5-9 mg/dL), or $>540 \mu \mathrm{mol} / \mathrm{L}(9 \mathrm{mg} / \mathrm{dL})$ in the cross-sectional analysis, as $390 \mu \mathrm{mol} / \mathrm{L}$ and $540 \mu \mathrm{mol} / \mathrm{L}$ represent the approximate IQR of the distribution. The univariate analysis of variance was used to measure the parametric distribution data among the groups or a Kruskal-Wallis test. For categorical data and proportions, the Bonferroni test was used to compare the difference among groups. The correlations between SUA and the associated factors for CKD were investigated using Pearson and Spearman correlation test. Since SBP, TC, Scr, BUN, Cys C, eGFR, and 24HUPr were not parametrically distributed, we used Spearman correlation analysis. We then used multiple logistic regression analysis to determine the association between potential associated factors and elevated SUA. The results were reported as odds ratios (ORs) with 95\% confidence intervals (CIs). Statistical significance for all analyses was set at $p<0.05$. Statistical analysis was performed with software SPSS 22.0.

\section{Results}

\subsection{Baseline Characteristics of the Study Population}

Totally 170 children were recruited, comprising 98 boys and 72 girls (42.35\%), with a mean age of $9.79 \pm 4.10$ years. General data appeared in Table 1. The mean SUA was $476.96 \pm 155.97 \mu \mathrm{mol} / \mathrm{L}$, and boys had greater SUA levels than girls (497.95 \pm 164.45 vs. $448.38 \pm 139.70 \mu \mathrm{mol} / \mathrm{L}, p=0.04)$. Boys were taller than girls $(132.11 \pm 26.80 \mathrm{vs}$. $126.09 \pm 25.30 \mathrm{~cm}, p=0.031)$. Median eGFR was $38.26 \mathrm{~mL} / \mathrm{min} / 1.73 \mathrm{~m}^{2}$. For the etiology of CKD in children, CAKUT had the highest proportion $(40.00 \%, 68 / 170)$. In addition, $28.82 \%$ (49/170) of CKD participants were diagnosed with glomerular diseases. Then, among the comorbidities of CKD, anemia accounted for 60.59\% (103/170), the highest proportion, followed by hypertension $55.89 \%$ (95/170). Obesity, short stature, and renal osteopathy accounted for $8.24 \%$ (14/170), 24.12\% (41/170), and 21.18\% (36/170), respectively.

Table 1 reported participants' characteristics stratified by serum uric acid $(<390 \mu \mathrm{mol} / \mathrm{L}$ (6.5 mg/dL; $n=52 ; 30.59 \%), 390-540 \mu \mathrm{mol} / \mathrm{L}(6.5-9.0 \mathrm{mg} / \mathrm{dL} ; n=62 ; 36.47 \%)$, and $>540 \mu \mathrm{mol} / \mathrm{L}(9.0 \mathrm{mg} / \mathrm{dL} ; n=56 ; 32.94 \%))$. The participants with $\mathrm{SUA}>540 \mu \mathrm{mol} / \mathrm{L}$ $(9.0 \mathrm{mg} / \mathrm{dL})$ had the highest BUN $(p<0.001)$, Cys C $(p<0.001)$, Scr $(p<0.001)$ and DD $(p=0.024)$ compared to the other two groups. Moreover, the lowest $\mathrm{Hb}(p=0.002)$ and eGFR levels were observed in participants with SUA $>540 \mu \mathrm{mol} / \mathrm{L}(9.0 \mathrm{mg} / \mathrm{dL})$. The participants with SUA $\geq 390 \mu \mathrm{mol} / \mathrm{L}$ (6.5 mg/dL) also had higher incidence of hypertension, anemia and renal osteopathy, compared to those with SUA $<390 \mu \mathrm{mol} / \mathrm{L}(6.5 \mathrm{mg} / \mathrm{dL})$. There were similar distributions of age, sex, BMI, BP, TC, TG, Fib, 24HUPr, and the incidence of CAKUT, obesity, hypertension, anemia, short stature, and renal osteopathy among three groups.

Table 1. Characteristics of the study population by category of serum uric acid.

\begin{tabular}{|c|c|c|c|c|c|}
\hline \multirow{2}{*}{ Characteristic } & \multirow{2}{*}{ Total $(n=170)$} & $<390 \mu \mathrm{mol} / \mathrm{L}(n=52)$ & $390-540 \mu \mathrm{mol} / \mathrm{L}(n=62)$ & $>540 \mu \mathrm{mol} / \mathrm{L}(n=56)$ & \multirow{2}{*}{$p^{*}$} \\
\hline & & $(<6.5 \mathrm{mg} / \mathrm{dL})$ & (6.5-9 mg/dL) & (>9.0 mg/dL) & \\
\hline Age (years) & $9.79 \pm 4.10$ & $9.44 \pm 4.44$ & $9.66 \pm 4.12$ & $10.24 \pm 3.75$ & 0.696 \\
\hline Boys (\%) & $99(58.23)$ & $25(48.08)$ & $38(61.29)$ & $36(64.29)$ & 0.193 \\
\hline $\operatorname{BMI}\left(\mathrm{kg} / \mathrm{m}^{2}\right)$ & $17.34 \pm 4.49$ & $16.04(14.69,18.66)$ & $15.88(14.47,19.19)$ & $16.58(14.57,19.58)$ & 0.589 \\
\hline $\mathrm{SBP}(\mathrm{mmHg})$ & $117.81 \pm 19.96$ & $115.83 \pm 21.48$ & $116.39 \pm 18.20$ & $121.21 \pm 20.29$ & 0.287 \\
\hline $\mathrm{DBP}(\mathrm{mmHg})$ & $74.69 \pm 17.88$ & $74.35 \pm 19.45$ & $72.98 \pm 15.83$ & $76.91 \pm 18.58$ & 0.501 \\
\hline $\mathrm{Hb}(\mathrm{g} / \mathrm{L})$ & $105.31 \pm 26.23$ & $114.62 \pm 23.09$ & $104.77 \pm 25.29$ & $97.27 \pm 27.60$ & 0.002 \\
\hline
\end{tabular}


Table 1. Cont.

\begin{tabular}{|c|c|c|c|c|c|}
\hline \multirow{2}{*}{ Characteristic } & \multirow{2}{*}{ Total $(n=170)$} & $<390 \mu \mathrm{mol} / \mathrm{L}(n=52)$ & $390-540 \mu \mathrm{mol} / \mathrm{L}(n=62)$ & $>540 \mu \mathrm{mol} / \mathrm{L}(n=56)$ & \multirow{2}{*}{$p^{*}$} \\
\hline & & $(<6.5 \mathrm{mg} / \mathrm{dL})$ & (6.5-9 mg/dL) & (>9.0 mg/dL) & \\
\hline $\mathrm{Alb}(\mathrm{g} / \mathrm{L})$ & $37.97 \pm 8.31$ & $42.35(36.53,45.95)$ & $38.10(31.78,42.48)$ & $38.75(34.18,42.68)$ & 0.047 \\
\hline $\mathrm{TC}(\mathrm{mmol} / \mathrm{L})$ & $5.32 \pm 2.56$ & $4.35(3.40,5.42)$ & $4.72(3.99,6.15)$ & $4.95(4.11,6.23)$ & 0.127 \\
\hline TG (mmol/L) & $2.37 \pm 1.89$ & $1.50(0.87,2.67)$ & $2.07(1.14,3.83)$ & $2.00(1.40,2.92)$ & 0.053 \\
\hline BUN (mmol/L) & $12.53(7.69,26.13)$ & $8.20(5.50,10.92)$ & $12.92(7.87,24.32)$ & $25.45(13.24,38.65)$ & $<0.001$ \\
\hline Cys C (mg/L) & $3.09 \pm 1.84$ & $1.46(1.16,2.71)$ & $2.61(1.49,4.24)$ & $4.11(2.36,5.43)$ & $<0.001$ \\
\hline $\operatorname{Scr}(\mu \mathrm{mol} / \mathrm{L})$ & $162.50(95.75,471.50)$ & $88.00(73.50,170.00)$ & $165.00(102.50,415.75)$ & $411.00(142.75,717.00)$ & $<0.001$ \\
\hline $\mathrm{eGFR}\left(\mathrm{mL} / \mathrm{min} / 1.73 \mathrm{~m}^{2}\right)$ & $38.26(12.68,66.91)$ & $64.87(29.91,90.62)$ & $38.63(13.24,66.75)$ & $16.57(9.22,38.83)$ & $<0.001$ \\
\hline $\mathrm{Fib}(\mathrm{g} / \mathrm{L})$ & $2.97 \pm 1.13$ & $2.47(1.98,3.26)$ & $2.88(2.32,3.57)$ & $2.84(2.34,3.67)$ & 0.156 \\
\hline $\mathrm{DD}(\mathrm{mg} / \mathrm{L})$ & $0.96 \pm 1.54$ & $0.41(0.22,0.90)$ & $0.41(0.20,0.94)$ & $0.76(0.38,1.51)$ & 0.024 \\
\hline $24 \operatorname{HUPr}\left(\mathrm{mg} / \mathrm{m}^{2} / \mathrm{d}\right)$ & $690.04(178.94,1710.18)$ & $547.41(77.56,1395.79)$ & $738.69(248.49,2058.53)$ & $673.16(194.90,1663.15)$ & 0.302 \\
\hline CAKUT $n(\%)$ & $68(40.00)$ & $19(36.54)$ & $22(35.48)$ & $27(48.21)$ & 0.307 \\
\hline Obesity $n(\%)$ & $14(8.24)$ & $5(9.62)$ & $6(9.68)$ & $3(5.36)$ & 0.633 \\
\hline Hypertension $n(\%)$ & $95(55.89)$ & $25(48.08)$ & $33(53.22)$ & $37(66.07)$ & 0.148 \\
\hline Anemia $n(\%)$ & $103(60.59)$ & $27(51.92)$ & $36(58.06)$ & $39(69.64)$ & 0.215 \\
\hline Short stature $n(\%)$ & $41(24.12)$ & $13(25.00)$ & $15(24.19)$ & $13(23.21)$ & 0.977 \\
\hline Renal osteopathy $n(\%)$ & $36(21.18)$ & $7(13.46)$ & $14(22.58)$ & $15(26.79)$ & 0.225 \\
\hline
\end{tabular}

Abbreviations: BMI body mass index, SBP systolic blood pressure, DBP diastolic blood pressure, Hb hemoglobin, Alb albumin, TC total cholesterol, TG triglycerides, BUN blood urea nitrogen, SUA serum uric acid, Cys C cystatin C, Scr serum creatinine, eGFR estimated glomerular filtration rate, Fib fibrinogen, DD D-Dimer, 24HUPr $24 \mathrm{~h}$ urine protein quantity, CAKUT congenital anomalies of the kidney and urinary tract. * Among three groups $(<390 \mu \mathrm{mol} / \mathrm{L}, 390-540 \mu \mathrm{mol} / \mathrm{L}$, and $>540 \mu \mathrm{mol} / \mathrm{L})$, the univariate analysis of variance was used for the parametric distribution data or a Kruskal-Wallis test. Bonferroni test was used for categorical data and proportions.

\subsection{Correlations between SUA and Associated Factors in Children with CKD}

Table 2 reported the results of the correlation analysis between SUA level and the associated factors for CKD. Pearson and Spearman correlation analysis showed that SUA levels were positively associated with TC $(\mathrm{r}=0.161, p=0.036)$, TG $(\mathrm{r}=0.208, p=0.007)$, Scr $(r=0.515, p<0.001)$, BUN $(r=0.558, p<0.001)$, Cys C $(r=0.488, p<0.001)$, and $\mathrm{DD}(\mathrm{r}=0.214, p=0.005)$. SUA levels showed significantly negative correlations with $\mathrm{Hb}$ $(\mathrm{r}=-0.281, p<0.001)$ and eGFR $(\mathrm{r}=-0.442, p<0.001)$.

Table 2. Correlations between SUA and associated factors for CKD.

\begin{tabular}{ccc}
\hline & \multicolumn{2}{c}{ SUA $(\boldsymbol{n}=\mathbf{1 7 0})$} \\
\cline { 2 - 3 } Characteristics & $\mathbf{r}$ & $\boldsymbol{p}$ \\
\hline Age (years) & -0.056 & 0.464 \\
$\mathrm{BMI}\left(\mathrm{kg} / \mathrm{m}^{2}\right)$ & -0.067 & 0.384 \\
$\mathrm{SBP}(\mathrm{mmHg})$ & 0.128 & 0.096 \\
$\mathrm{DBP}(\mathrm{mmHg})$ & 0.05 & 0.515 \\
$\mathrm{Hb}(\mathrm{g} / \mathrm{L})$ & -0.281 & $<0.001$ \\
$\mathrm{Alb}(\mathrm{g} / \mathrm{L})$ & -0.148 & 0.053 \\
$\mathrm{TC}(\mathrm{mmol} / \mathrm{L})$ & 0.161 & 0.036 \\
$\mathrm{TG}(\mathrm{mmol} / \mathrm{L})$ & 0.208 & 0.007 \\
$\mathrm{Scr}(\mu \mathrm{mol} / \mathrm{L})$ & 0.515 & $<0.001$ \\
$\mathrm{BUN}(\mathrm{mmol} / \mathrm{L})$ & 0.558 & $<0.001$ \\
$\mathrm{Cys} \mathrm{C}(\mathrm{mg} / \mathrm{L})$ & 0.488 & $<0.001$ \\
$\mathrm{Fib}(\mathrm{g} / \mathrm{L})$ & 0.051 & 0.506 \\
$\mathrm{DD}(\mathrm{mg} / \mathrm{L})$ & 0.214 & 0.005 \\
eGFR $\left(\mathrm{mL} / \mathrm{min} / 1.73 \mathrm{~m}^{2}\right)$ & -0.442 & $<0.001$ \\
$24 \mathrm{HUPr}\left(\mathrm{mg} / \mathrm{m}^{2} / \mathrm{d}\right)$ & 0.089 & 0.247 \\
\hline
\end{tabular}

Abbreviations: BMI body mass index, SBP systolic blood pressure, DBP diastolic blood pressure, Hb hemoglobin Alb albumin, TC total cholesterol, TG triglycerides, BUN blood urea nitrogen, SUA serum uric acid, Cys C cystatin C, Scr serum creatinine, eGFR estimated glomerular filtration rate, Fib fibrinogen, DD D-Dimer, 24HUPr $24 \mathrm{~h}$ urine protein quantity.

\subsection{Relationship between Elevated SUA and Associated Factors}

Table 3 showed the results of multiple logistic regression analysis between elevated SUA $(\geq 390 \mu \mathrm{mol} / \mathrm{L}, 6.5 \mathrm{mg} / \mathrm{dL})$ and associated factors for CKD. Anemia and higher BUN were both 
independently associated with a higher risk of elevated SUA (OR: 3.619 (95\% CI: 1.322-9.905), OR: 1.113 (95\% CI: 1.032-1.200), respectively). In addition, eGFR $\geq 90 \mathrm{~mL} / \mathrm{min} / 1.73 \mathrm{~m}^{2}$ exhibited an OR of 0.116 (95\% CI: $0.025-0.532)$ for elevated SUA compared with eGFR $<60 \mathrm{~mL} / \mathrm{min}$ / $1.73 \mathrm{~m}^{2}$.

Table 3. Results of multiple logistic regression analysis between elevated SUA and associated factors.

\begin{tabular}{ccc}
\hline Characteristics & Elevated SUA (OR, 95\% CI) & $p$ \\
\hline Sex (boys vs. girls) & $2.122(0.917,4.914)$ & 0.079 \\
Age (years) & $1.060(0.959,1.172)$ & 0.251 \\
BMI $>$ 95th percentile (vs. $\leq 95$ th) & $0.947(0.235,3.907)$ & 0.938 \\
CAKUT & $1.540(0.660,3.594)$ & 0.318 \\
Hypertension & $0.978(0.441,2.169)$ & 0.957 \\
Anemia & $3.619(1.322,9.905)$ & 0.012 \\
Elevated TC & $1.814(0.719,4.578)$ & 0.207 \\
Elevated TG & $0.697(0.272,1.790)$ & 0.453 \\
BUN & $1.113(1.032,1.200)$ & 0.006 \\
Cys C & $0.918(0.579,1.456)$ & 0.716 \\
eGFR (mL/min/1.73 $\left.\mathrm{m}^{2}\right)$ & & \\
$<60$ (reference) & 1 & 0.099 \\
60-89 & $0.386(0.125,1.195)$ & 0.006 \\
$\geq 90$ & $0.116(0.025,0.532)$ & \\
\hline
\end{tabular}

Abbreviations: BMI body mass index, CAKUT congenital anomalies of the kidney and urinary tract, TC total cholesterol, TG triglycerides, BUN blood urea nitrogen, SUA serum uric acid, Cys C cystatin C, eGFR estimated glomerular filtration rate.

\section{Discussion}

The relationship between elevated SUA and metabolic syndrome, cardiovascular diseases, and kidney diseases has been reported in adults and children, but the data are inconsistent, and the results are still controversial. Our study clearly demonstrated associated factors with hyperuricemia in Chinese CKD children for the first time.

Uric acid is a purine metabolite generated in the liver and mostly excreted in the urine [27]. SUA level in children is related to age and sex. There are no universally accepted clinical diagnostic criteria for hyperuricemia in children. During adolescence, boys had higher uric acid levels than similarly aged girls due to lower estrogen levels, increased BMI, and declined fractional excretion of urate $[28,29]$. In America, hyperuricemia was defined that SUA levels were $\geq 7.0 \mathrm{mg} / \mathrm{dL}$ in males and $\geq 6.0 \mathrm{mg} / \mathrm{dL}$ in females [23]. In Japan, when pediatric patients visited medical clinics, biochemical items, including SUA, in many cases, were measured [2]. The diagnostic criteria for hyperuricemia in Japanese children was based on the cutoffs, which were $5.9 \mathrm{mg} / \mathrm{dL}$ for 6-8 years (both genders), $6.1 \mathrm{mg} / \mathrm{dL}$ for $9-11$ years (both genders), $7.0 \mathrm{mg} / \mathrm{dL}$ (males), and $6.2 \mathrm{mg} / \mathrm{dL}$ (females) for 12-14 years [30,31]. In the present study, we found that SUA levels were lower in girls, which supported the previous work. Moreover, the percentage of boys with SUA $\geq 390 \mu \mathrm{mol} / \mathrm{L}(6.5 \mathrm{mg} / \mathrm{dL})$ was greater than those with SUA $<390 \mu \mathrm{mol} / \mathrm{L}(6.5 \mathrm{mg} / \mathrm{dL})$. However, the boy sex with CKD was not significantly associated with elevated SUA (OR: 2.122 (95\% CI: 0.917, 4.914)) in the multiple logistic regression analysis. These findings suggested that sex difference was not associated with elevated SUA in CKD children. Together, we estimated that sex differences in SUA levels would continue from adolescence into adulthood, and boys may tolerate higher SUA levels than girls.

This study showed that anemia was positively associated with SUA $\geq 390 \mu \mathrm{mol} / \mathrm{L}$ $(6.5 \mathrm{mg} / \mathrm{dL})$. Anemia is a common comorbidity of CKD and has been identified as a risk factor for the progression of CKD [32,33]. Hyperuricemia is prevalent in sickle cell anemia (SCA) patients [34-36]. In cross-sectional studies of children with SCA, those with hyperuricemia had a lower eGFR than those without hyperuricemia [34,35]. Additionally, a prospective study reported that the eGFR of SCA children with hyperuricemia declined more quickly during adolescence [36]. Hyperuricemia and anemia are both independent risk factors for CKD. However, the relationship between hyperuricemia and anemia in 
CKD children has not been adequately studied. Additional prospective studies are needed to determine the relationship between hyperuricemia and anemia in the setting and the development of CKD in children.

Studies have suggested that elevated SUA levels were associated with hypertension in CKD [4,37-40]. Animal experiments have reported that elevated SUA levels can activate the renin-angiotensin-aldosterone system and the sympathetic nervous system, mediate endothelial dysfunction, and increase oxidative stress and inflammation, resulting in vasoconstriction and hypertension $[4,39,40]$. A large study of 2373 high school people found that SUA level had become the most important SBP determinant [38]. A small $(n=63)$ study of pediatric hemodialysis patients found that pre-treatment SBP was associated with a higher SUA level [37]. In contrast, we found that hypertension was not associated with elevated SUA in CKD children. It was likely that blood pressure had a weaker relationship with SUA in children, possibly related to sex hormones, growth, and other variables.

Numerous studies have noted that elevated SUA level is associated with an increased risk of the progression of CKD in the general population [29,41-43]. However, not all findings have been positive, and related studies in children are still limited. In a study of 678 participants aged $\leq 15.6$ years, researchers found that those with SUA $>7.5 \mathrm{mg} / \mathrm{dL}$ had faster progression to $>30 \%$ decline in GFR [8]. Moreover, a randomized clinical trial including 113 participants showed that urate-lowering treatment with allopurinol may decrease the rate of decline in kidney function [44]. However, a recent randomized clinical trial of 363 adults with stage 3-4 CKD found that allopurinol did not slow the progression of CKD compared with placebo [45]. In another randomized clinical trial of 70 children with CKD stages 1-3, allopurinol can improve renal function [46]. Our study showed that eGFR $\geq 90 \mathrm{~mL} / \mathrm{min} / 1.73 \mathrm{~m}^{2}$ was a protective factor for elevated SUA in CKD children. We also observed that a higher BUN level was positively associated with SUA $\geq 390 \mu \mathrm{mol} / \mathrm{L}$ $(6.5 \mathrm{mg} / \mathrm{dL})$. Those would suggest that early detection and early treatment of hyperuricemia for CKD children might retard the progression of CKD but need to be explored further.

Our study has several limitations. Firstly, this study was a cross-sectional study based on information from the hospital, so it was hard to infer a causal relationship between exposure and outcomes. Moreover, these data from the hospital from 2013 to 2020 were a little unreliable because of the changes of the devices, the conditions, and the methods over time. Furthermore, we used eGFR estimated by the Schwartz formula rather than direct measurements to evaluate kidney function [15]. The Schwartz formula, which was developed in American children, might be unsuitable for Chinese children to estimate the GFR. Finally, patients who are hospitalized at this hospital might have more severe clinical symptoms than outpatients, and the data from those patients might overestimate associated factors.

\section{Conclusions}

In conclusion, we demonstrate that SUA was significantly associated with anemia, BUN, and eGFR in Chinese CKD children for the first time. Our findings emphasize the importance of early monitoring serum uric acid levels in the development and progression of CKD in children. Further multicenter, maximus sample, and prospective studies are needed to reveal the actual relationship between hyperuricemia and associated factors in Chinese CKD children.

Author Contributions: J.X. and L.T. participated in the collection of the clinical data and the data analysis. J.X. and L.T. wrote the manuscript. J.M. conceived the study design, contributed to the data analysis and interpretation, reviewed and edited the manuscript. All authors have read and agreed to the published version of the manuscript.

Funding: This research was funded by the National Natural Science Foundation of China (U20A20351, 81870314), The Major Scientific and Technological Project of Zhejiang Province (2021C03079, 2019C03028). 
Institutional Review Board Statement: The study was conducted according to the guidelines of the Declaration of Helsinki and approved by the Institutional Review Board of the Children's Hospital, Zhejiang University School of Medicine (protocol code: 2017-IRB-011; date of approval: 20 May 2017).

Informed Consent Statement: Informed consent was waived due to the retrospective character of the study.

Data Availability Statement: The data sets used and/or analyzed during the current study are available from the corresponding author on reasonable request.

Acknowledgments: We thank the patients and their families for participating in this study.

Conflicts of Interest: The authors declare no conflict of interest.

\section{References}

1. Li, N.; Zhang, S.; Li, W.; Wang, L.; Liu, H.; Li, W.; Zhang, T.; Liu, G.; Du, Y.; Leng, J. Prevalence of hyperuricemia and its related risk factors among preschool children from China. Sci. Rep. 2017, 7, 9448. [CrossRef] [PubMed]

2. Ito, S.; Torii, T.; Nakajima, A.; Iijima, T.; Murano, H.; Horiuchi, H.; Yamanaka, H.; Honda, M. Prevalence of gout and asymptomatic hyperuricemia in the pediatric population: A cross-sectional study of a Japanese health insurance database. BMC Pediatr. 2020, 20, 481. [CrossRef] [PubMed]

3. Wei, Y.; Zhu, J.; Wetzstein, S.A. Plasma and water fluoride levels and hyperuricemia among adolescents: A cross-sectional study of a nationally representative sample of the United States for 2013-2016. Ecotoxicol. Environ. Saf. 2021, 208, 111670. [CrossRef]

4. Feig, D.I. Serum uric acid and the risk of hypertension and chronic kidney disease. Curr. Opin. Rheumatol. 2014, 26, 176-185. [CrossRef]

5. Dawson, J.; Jeemon, P.; Hetherington, L.; Judd, C.; Hastie, C.; Schulz, C.; Sloan, W.; Muir, S.; Jardine, A.; McInnes, G.; et al. Serum uric acid level, longitudinal blood pressure, renal function, and long-term mortality in treated hypertensive patients. Hypertension 2013, 62, 105-111. [CrossRef]

6. Krishnan, E.; Akhras, K.S.; Sharma, H.; Marynchenko, M.; Wu, E.; Tawk, R.H.; Liu, J.; Shi, L. Serum urate and incidence of kidney disease among veterans with gout. J. Rheumatol. 2013, 40, 1166-1172. [CrossRef]

7. Kuwabara, M.; Kuwabara, R.; Hisatome, I.; Niwa, K.; Roncal-Jimenez, C.A.; Bjornstad, P.; Andres-Hernando, A.; Sato, Y.; Jensen, T.; Garcia, G.; et al. "Metabolically Healthy" Obesity and Hyperuricemia Increase Risk for Hypertension and Diabetes: 5-year Japanese Cohort Study. Obesity (Silver Spring) 2017, 25, 1997-2008. [CrossRef] [PubMed]

8. Rodenbach, K.E.; Schneider, M.F.; Furth, S.L.; Moxey-Mims, M.M.; Mitsnefes, M.M.; Weaver, D.J.; Warady, B.A.; Schwartz, G.J. Hyperuricemia and Progression of CKD in Children and Adolescents: The Chronic Kidney Disease in Children (CKiD) Cohort Study. Am. J. Kidney Dis. 2015, 66, 984-992. [CrossRef]

9. Johnson, R.J.; Bakris, G.L.; Borghi, C.; Chonchol, M.B.; Feldman, D.; Lanaspa, M.A.; Merriman, T.R.; Moe, O.W.; Mount, D.B.; Sanchez Lozada, L.G.; et al. Hyperuricemia, Acute and Chronic Kidney Disease, Hypertension, and Cardiovascular Disease: Report of a Scientific Workshop Organized by the National Kidney Foundation. Am. J. Kidney Dis. 2018, 71, 851-865. [CrossRef] [PubMed]

10. Calderon-Margalit, R.; Golan, E.; Twig, G.; Leiba, A.; Tzur, D.; Afek, A.; Skorecki, K.; Vivante, A. History of Childhood Kidney Disease and Risk of Adult End-Stage Renal Disease. N. Engl. J. Med. 2018, 378, 428-438. [CrossRef]

11. Lipkowitz, M.S. Regulation of uric acid excretion by the kidney. Curr. Rheumatol. Rep. 2012, 14, 179-188. [CrossRef]

12. Li, P.; Zhang, L.; Zhang, M.; Zhou, C.; Lin, N. Uric acid enhances PKC-dependent eNOS phosphorylation and mediates cellular ER stress: A mechanism for uric acid-induced endothelial dysfunction. Int. J. Mol. Med. 2016, 37, 989-997. [CrossRef]

13. Kanbay, M.; Yilmaz, M.I.; Sonmez, A.; Turgut, F.; Saglam, M.; Cakir, E.; Yenicesu, M.; Covic, A.; Jalal, D.; Johnson, R.J. Serum uric acid level and endothelial dysfunction in patients with nondiabetic chronic kidney disease. Am. J. Nephrol. 2011, 33, $298-304$. [CrossRef]

14. Valle, M.; Martos, R.; Canete, M.D.; Valle, R.; van Donkelaar, E.L.; Bermudo, F.; Canete, R. Association of serum uric acid levels to inflammation biomarkers and endothelial dysfunction in obese prepubertal children. Pediatr. Diabetes 2015, 16, $441-447$. [CrossRef]

15. Schwartz, G.J.; Brion, L.P.; Spitzer, A. The Use of Plasma Creatinine Concentration for Estimating Glomerular Filtration Rate in Infants, Children, and Adolescents. Pediatric Clin. N. Am. 1987, 34, 571-590. [CrossRef]

16. Grummer-Strawn, L.M.; Reinold, C.; Krebs, N.F. Use of World Health Organization and CDC growth charts for children aged 0-59 months in the United States. MMWR Recomm. Rep. 2010, 59, 1-15. [PubMed]

17. Flynn, J.T.; Kaelber, D.C.; Baker-Smith, C.M.; Blowey, D.; Carroll, A.E.; Daniels, S.R.; de Ferranti, S.D.; Dionne, J.M.; Falkner, B.; Flinn, S.K.; et al. Clinical Practice Guideline for Screening and Management of High Blood Pressure in Children and Adolescents. Pediatrics 2017, 140, e20171904. [CrossRef] [PubMed]

18. Levin, A.; Stevens, P.; Bilous, R.W.; Coresh, J.; Francisco, A.; Jong, P.E.; Griffith, K.E.; Hemmelgarn, B.R.; Iseki, K.; Lamb, E.; et al. Kidney disease: Improving global outcomes (KDIGO) CKD work group. KDIGO 2012 clinical practice guideline for the evaluation and management of chronic kidney disease. Kidney Int. Suppl. 2013, 3, 1-150. 
19. Tomson, C.R.V.; Cheung, A.K.; Mann, J.F.E.; Chang, T.I.; Cushman, W.C.; Furth, S.L.; Hou, F.F.; Knoll, G.A.; Muntner, P.; PecoitsFilho, R.; et al. Management of Blood Pressure in Patients with Chronic Kidney Disease Not Receiving Dialysis: Synopsis of the 2021 KDIGO Clinical Practice Guideline. Ann. Intern. Med. 2021, 174, 1270-1281. [CrossRef]

20. Warady, B.A.; Chadha, V. Chronic kidney disease in children: The global perspective. Pediatr. Nephrol. 2007, 22, 1999-2009. [CrossRef] [PubMed]

21. Cohen, L.E. Idiopathic short stature: A clinical review. JAMA 2014, 311, 1787-1796. [CrossRef]

22. Expert Panel on Integrated Guidelines for Cardiovascular Health and Risk Reduction in Children and Adolescents; National Heart, Lung, and Blood Institute. Expert panel on integrated guidelines for cardiovascular health and risk reduction in children and adolescents: Summary report. Pediatrics 2011, 128 (Suppl. S5), S213-S256.

23. Odden, M.C.; Amadu, A.R.; Smit, E.; Lo, L.; Peralta, C.A. Uric acid levels, kidney function, and cardiovascular mortality in US adults: National Health and Nutrition Examination Survey (NHANES) 1988-1994 and 1999-2002. Am. J. Kidney Dis. 2014, 64, 550-557. [CrossRef]

24. Zhang, L.; Wang, F.; Wang, L.; Wang, W.; Liu, B.; Liu, J.; Chen, M.; He, Q.; Liao, Y.; Yu, X.; et al. Prevalence of chronic kidney disease in China: A cross-sectional survey. Lancet 2012, 379, 815-822. [CrossRef]

25. Uchida, S.; Chang, W.X.; Ota, T.; Tamura, Y.; Shiraishi, T.; Kumagai, T.; Shibata, S.; Fujigaki, Y.; Hosoyamada, M.; Kaneko, K.; et al. Targeting Uric Acid and the Inhibition of Progression to End-Stage Renal Disease-A Propensity Score Analysis. PLoS ONE 2015, 10, e0145506. [CrossRef]

26. Domrongkitchaiporn, S.; Sritara, P.; Kitiyakara, C.; Stitchantrakul, W.; Krittaphol, V.; Lolekha, P.; Cheepudomwit, S.; Yipintsoi, T. Risk factors for development of decreased kidney function in a southeast Asian population: A 12-year cohort study. J. Am. Soc. Nephrol. 2005, 16, 791-799. [CrossRef]

27. Mandal, A.K.; Mount, D.B. The molecular physiology of uric acid homeostasis. Annu. Rev. Physiol. 2015, 77, 323-345. [CrossRef]

28. Stiburkova, B.; Bleyer, A.J. Changes in serum urate and urate excretion with age. Adv. Chronic Kidney Dis. 2012, 19, 372-376. [CrossRef]

29. Madero, M.; Sarnak, M.J.; Wang, X.; Greene, T.; Beck, G.J.; Kusek, J.W.; Collins, A.J.; Levey, A.S.; Menon, V. Uric acid and long-term outcomes in CKD. Am. J. Kidney Dis. 2009, 53, 796-803. [CrossRef]

30. Kubota, M. Hyperuricemia in Pediatric Field. Gout Nucleic ACID Metab. 2009, 33, 37-43. [CrossRef]

31. Kubota, M. Hyperuricemia in Children and Adolescents: Present Knowledge and Future Directions. J. Nutr. Metab. 2019, 2019, 3480718. [CrossRef]

32. Stauffer, M.E.; Fan, T. Prevalence of anemia in chronic kidney disease in the United States. PLoS ONE 2014, 9, e84943.

33. St Peter, W.L.; Guo, H.; Kabadi, S.; Gilbertson, D.T.; Peng, Y.; Pendergraft, T.; Li, S. Prevalence, treatment patterns, and healthcare resource utilization in Medicare and commercially insured non-dialysis-dependent chronic kidney disease patients with and without anemia in the United States. BMC Nephrol. 2018, 19, 67. [CrossRef]

34. Lebensburger, J.D.; Cutter, G.R.; Howard, T.H.; Muntner, P.; Feig, D.I. Evaluating risk factors for chronic kidney disease in pediatric patients with sickle cell anemia. Pediatr. Nephrol. 2017, 32, 1565-1573. [CrossRef]

35. Kaspar, C.D.W.; Beach, I.; Newlin, J.; Sisler, I.; Feig, D.; Smith, W. Hyperuricemia is associated with a lower glomerular filtration rate in pediatric sickle cell disease patients. Pediatr. Nephrol. 2020, 35, 883-889. [CrossRef]

36. Lebensburger, J.D.; Aban, I.; Hilliard, L.M.; Feig, D.I. Hyperuricemia and abnormal nocturnal dipping impact glomerular filtration rate in patients with sickle cell anemia. Am. J. Hematol. 2021, 96, E143-E146. [CrossRef] [PubMed]

37. Silverstein, D.M.; Srivaths, P.R.; Mattison, P.; Upadhyay, K.; Midgley, L.; Moudgil, A.; Goldstein, S.L.; Feig, D.I. Serum uric acid is associated with high blood pressure in pediatric hemodialysis patients. Pediatr. Nephrol. 2011, 26, 1123-1128. [CrossRef]

38. Sidoti, A.; Nigrelli, S.; Rosati, A.; Bigazzi, R.; Caprioli, R.; Fanelli, R.; Acconcia, P.; Borracelli, D.; Biagioli, M.; Angelini, D.; et al. Body mass index, fat free mass, uric acid, and renal function as blood pressure levels determinants in young adults. Nephrology (Carlton) 2017, 22, 279-285. [CrossRef]

39. Sánchez-Lozada, L.G.; Tapia, E.; López-Molina, R.; Nepomuceno, T.; Soto, V.; Avila-Casado, C.; Nakagawa, T.; Johnson, R.J.; Herrera-Acosta, J.; Franco, M. Effects of acute and chronic L-arginine treatment in experimental hyperuricemia. Am. J. Physiol. Renal. Physiol. 2007, 292, F1238-F1244. [CrossRef]

40. Mazzali, M.; Hughes, J.; Kim, Y.G.; Jefferson, J.A.; Kang, D.H.; Gordon, K.L.; Lan, H.Y.; Kivlighn, S.; Johnson, R.J. Elevated uric acid increases blood pressure in the rat by a novel crystal-independent mechanism. Hypertension 2001, 38, 1101-1106. [CrossRef]

41. Oh, T.R.; Choi, H.S.; Kim, C.S.; Bae, E.H.; Ma, S.K.; Sung, S.A.; Kim, Y.S.; Oh, K.H.; Ahn, C.; Kim, S.W. Hyperuricemia has increased the risk of progression of chronic kidney disease: Propensity score matching analysis from the KNOW-CKD study. Sci Rep. 2019, 9, 6681. [CrossRef] [PubMed]

42. Chonchol, M.; Shlipak, M.G.; Katz, R.; Sarnak, M.J.; Newman, A.B.; Siscovick, D.S.; Kestenbaum, B.; Carney, J.K.; Fried, L.F. Relationship of uric acid with progression of kidney disease. Am. J. Kidney Dis. 2007, 50, 239-247. [CrossRef]

43. Tan, V.S.; Garg, A.X.; McArthur, E.; Lam, N.N.; Sood, M.M.; Naylor, K.L. The 3-Year Incidence of Gout in Elderly Patients with CKD. Clin. J. Am. Soc. Nephrol. 2017, 12, 577-584. [CrossRef] [PubMed]

44. Goicoechea, M.; Garcia de Vinuesa, S.; Verdalles, U.; Verde, E.; Macias, N.; Santos, A.; Perez de Jose, A.; Cedeno, S.; Linares, T.; Luno, J. Allopurinol and progression of CKD and cardiovascular events: Long-term follow-up of a randomized clinical trial. Am. J. Kidney Dis. 2015, 65, 543-549. [CrossRef] [PubMed] 
45. Badve, S.V.; Pascoe, E.M.; Tiku, A.; Boudville, N.; Brown, F.G.; Cass, A.; Clarke, P.; Dalbeth, N.; Day, R.O.; de Zoysa, J.R.; et al. Effects of Allopurinol on the Progression of Chronic Kidney Disease. N. Engl. J. Med. 2020, 382, 2504-2513. [CrossRef] [PubMed]

46. Ghane Sharbaf, F.; Assadi, F. Effect of allopurinol on the glomerular filtration rate of children with chronic kidney disease. Pediatr. Nephrol. 2018, 33, 1405-1409. [CrossRef] 